\title{
EJNSO
}

\section{Effectiveness of Epley's Repositioning Maneuver in the Treatment of Benign Paroxysmal Positional Vertigo}

\author{
Ali Khalaf Mahrous, Ahmed Mohammed Ahmed Mahmoud, Hatem Salah Eldin El \\ Habashy, Mohammed Mohsen Sarhan
}

Department of Otorhinolaryngology, Al-Hussein University Hospital, Faculty of Medicine, Al-Azhar University, Cairo, Egypt.

\begin{abstract}
:
Introduction: Benign paroxysmal positional vertigo (BPPV) originating from the posterior semicircular canal is a common vestibular disorder that can be diagnosed and treated in outpatient clinic.

Objectives: The aim of this study is to assess the effectiveness of Epley's maneuver in management of patients with BPPV of the posterior semicircular canal.
\end{abstract}

Patients and Methods: This is a retrospective study of total of thirty patients with a diagnosis of BPPV of posterior semicircular canal. These patients were between the age of 20 and 60 years. This study was performed in the Audio-Vestibular Unit, Otorhinolaryngology department, Al-Hussein University Hospital between September 2018 and June 2019. Patients were examined by Dix-Halpike test then treated by Epley's maneuver.

Results: BPPV of the posterior canal was more common after the age of 40 years old and more common in females than males by a ratio of $3.3: 1$, with two types: unilateral (90\%) and bilateral (10\%). The left ear was more common than the right ear by a ratio of 1.46:1. The success rate of Epley's maneuver was 90\%.

Conclusion: In our experience, Epley's maneuver was successful in $90 \%$ of cases who presented with posterior canal BPPV. This tallies with the world literature in terms of the success rate.

Key words: Benign Paroxysmal Positional Vertigo, BPPV, Posterior Semicircular Canal, Dix-Halpike test, Epley's maneuver.

\section{Introduction}

Balance is the ability to maintain the body's center of mass over its base of support. It is achieved and maintained by a complex set of sensorimotor control systems that include sensory input from vision, proprioception, and the vestibular system (motion, equilibrium, spatial orientation). The vestibular system includes the parts of the inner ear and brainstem that process the sensory information involved with controlling balance and eye movements. If disease or injury damages these processing areas, vestibular disorders will result. Benign paroxysmal positional vertigo (BPPV) is one of the most common causes of vertigo ${ }^{1}$.

BPPV: Benign "it is not lifethreatening", Paroxysmal "it comes in 
bouts", Positional "it gets triggered by certain head positions or movements", Vertigo "illusion of movement". BPPV can affect people of any age but commonly presents at around 50 years of age. Younger people may develop BPPV as a consequence of head trauma. Women are affected twice as often as men. BPPV is considered 'benign' but may increase the risk of falls and injuries and make some occupations impossible (e.g., airline pilot $)^{2}$.

BPPV presents with brief periods of vertigo experienced with a change in the position of the person's head relative to gravity. BPPV is a mechanical disorder of the inner ear caused by abnormal stimulation of one or more of the three semicircular canals (SCCs). It occurs when some of the calcium carbonate crystals (otolith) that are normally embedded in gelatinous membrane (otoconial membrane) in the utricle become dislodged and fall into one or more of the 3 fluid-filled semicircular canals, where they are not supposed to be ${ }^{3}$.

The otoconia from the utricle dislodge and settle within one of the three SCCs changing the fluid filled canal dynamics from detecting rotation of the canals to detecting gravitation forces on the head. With BPPV, changing the plane of the involved canal relative to gravity causes debris to settle to the lowest part of the canal, changing the fluid pressure across the cupula, deflecting the hair cells, and generating the characteristic ocular nystagmus with associated vertigo. There are three mechanisms of BPPV, the most common being debris within the long arm of the canal called canalithiasis. Debris may also be found in the short arm of the canal or attached to the cupula weighting the membrane called cupulolithiasis. The most common canal involved is the posterior semicircular canal (PC) ${ }^{4}$.
The diagnosis of BPPV is based on history and findings on testing ${ }^{5}$.

If patients complain of vertigo with rolling in bed or getting out of bed, patients are 4.3 times more likely to have $\mathrm{BPPV}^{6}$.

\section{Patients and Methods:}

\section{Patients:}

This is a retrospective study of total of thirty patients with a diagnosis of Posterior Canal (PC)-BPPV. The age of the patients ranged from 20 and 60 years old. This study was performed in the Audio and Balance Unit, Otorhinolaryngology department, AlHussein University Hospital between September 2018 and June 2019.

\section{Ethical approval:}

The study was approved by the Ethics Board of Al-Azhar University. Verbal consent from all the patients for performing Dix-Hallpike test and Epley's maneuver were obtained.

\section{Inclusion Criteria:}

Patients with posterior type BPPV who fulfilled the following criteria:

- No age or sex limitation.

- Normal otoscopic findings.

- Normal middle ear function.

- Symptoms suggestive BPPV and confirmed with positive DixHallpike test.

\section{Exclusion Criteria:}

Patients with cervical spine condition or recent IOL (intraocular lens) or other types of vertigo and patients with PC-BPPV combined with any systemic or local diseases.

\section{Methods:}

Thorough history taking followed by clinical examination. Those patients with positive Dix-Halpike test who fulfilled the inclusion criteria were enrolled in our study after taking a verbal consent. We have asked them to fill-in a questionnaire "Arabic translated - dizziness handicap 
inventory, DHI"7 first before performing Epley's maneuver and one a week after the maneuver. If anyone of them was still symptomatic, we repeated Epley's maneuver. Finally, we requested only those patients who repeated Epley's maneuver to come back after one month from the initial maneuver to fill-in another questionnaire "the same form of the Arabic translated DHI questionnaire".

The DHI consists of 25 questions: Seven questions deal with physical aspects; nine questions evaluate the emotional aspects and a further nine questions assess the functional aspects. Patients answer with "yes", "no" or "sometimes" Appendix (1).

"Yes" answers score four points, "no" answers score zero and "sometimes" scores two points. The maximum score is 28 for the physical aspects, 36 points for the emotional aspects and 36 points for the functional aspects, totaling 100 points.

In attempt to evaluate the degree of handicap, a score up to $25 \%$ is considered mild handicap (which indicates normal person), 26-50\% was considered moderate handicap, 51-75\% was considered as moderately severe handicap and $>75 \%$ was considered as a severe handicap ${ }^{7}$.

\section{Statistical analysis :}

Data were coded and entered using the statistical package for the Social Sciences (SPSS) version 25 (IBM Corp., Armonk, NY, USA).

For comparison of serial measurements within each patient the non-parametric Wilcoxon signed rank test was used. For comparing categorical data, Chi square $(\chi 2)$ test was performed. Exact test was used instead when the expected frequency is less than 5. Correlations between quantitative variables were done using Spearman correlation coefficient.

\section{Results:}

This is a retrospective study for evaluation of the effectiveness of Epley's maneuver in management of patients with BPPV of the posterior SCC. The study was conducted on 30 patients with documented BPPV either unilateral or bilateral. Diagnosis of posterior canal BPPV was done based upon history and positive Dix-Hallpike test. The demographic data were presented in table1.

Table (1): Demographic data of patients in this study.

\begin{tabular}{|c|c|c|c|}
\hline & & No. & $\%$ \\
\hline \multirow{2}{*}{ Age group } & $<=40$ & 10 & $33.3 \%$ \\
\hline & $>40$ & 20 & $66.7 \%$ \\
\hline \multirow{2}{*}{ Gender } & Male & 7 & $23.3 \%$ \\
\hline & Female & 23 & $76.7 \%$ \\
\hline \multirow{2}{*}{$\begin{array}{c}\text { Unilateral } \\
\text { or bilateral }\end{array}$} & Unilateral & 27 & $90.0 \%$ \\
\hline & Bilateral & 3 & $10.0 \%$ \\
\hline \multirow{2}{*}{ Side } & $\begin{array}{l}\text { Left side } \\
\text { affected }\end{array}$ & 16 & $59.3 \%$ \\
\hline & $\begin{array}{l}\text { Right side } \\
\text { affected }\end{array}$ & 11 & $40.7 \%$ \\
\hline
\end{tabular}

The age of patients included in this study was ranging from 20 years old to 60 years old. Mean age in all patients was $43.43 \pm 8.99$ years old. The prescoring of those patients was ranging from 28 point to 78 point with mean pre-scoring of $57.45 \pm 12.72 \mathrm{Pt}$. The post-scoring of those patients was ranging from $2 \mathrm{Pt}$ to $52 \mathrm{Pt}$ with mean post-scoring of $15.64 \pm 13.17 \mathrm{Pt}$. (Table 2).

Posterior canal BPPV is more common after the age of 40 years old as it was found in 10 patients under the age of 40 and in 20 patients after the age of 40 according this study. 
Table (2): Description of age and scoring of patients included in this study

\begin{tabular}{|c|c|c|c|c|c|}
\hline & Mean & SD & Median & Minimum & Maximum \\
\hline Age & 43.43 & 8.99 & 44.00 & 20.00 & 60.00 \\
\hline $\begin{array}{c}\text { pre- } \\
\text { scoring }\end{array}$ & 57.45 & 12.72 & 58.00 & 28.00 & 78.00 \\
$\begin{array}{c}\text { post- } \\
\text { scoring }\end{array}$ & 15.64 & 13.17 & 12.00 & 2.00 & 52.00 \\
\hline
\end{tabular}

It is more common in females than males as it was found in 23 female patients while it was found only in 7 male patients. Unilateral PC-BPPV is more common than bilateral PC-BPPV as it was found in 27 patients while bilateral type was found in 3 cases only. The left ear PC-BPPV is more common than the right ear as it was found in 16 patients while the rightside affection was found in 11 patients. (Table 1).

In cases with bilateral BPPV, we considered this patient as two separate patients each had unilateral affection. we began Epley's maneuver on the more affected side. And after a week, the patient was reassessed by answering the Arabic translated dizziness handicap inventory (DHI) and Epley's maneuver was performed on the other side. Then the patient was reassessed one more time by answering the Arabic translated dizziness handicap inventory (DHI) after a week. In this study, the number of recorded patients was 30 (27 unilateral cases and 3 bilateral cases). So we considered that we got 33 patients. By another mean, we got 30 patients with 33 affected ears.

The higher the frequency of attacks, the higher the scoring and grading of the patient.

Based on this table, the higher the grade, the greater the need for another session. The moderately-severe grade is the most common grade in this study as it was found in 19 patients in the study. Almost all cases in this study became mild grade (which is normal person) except in 4 patients only.

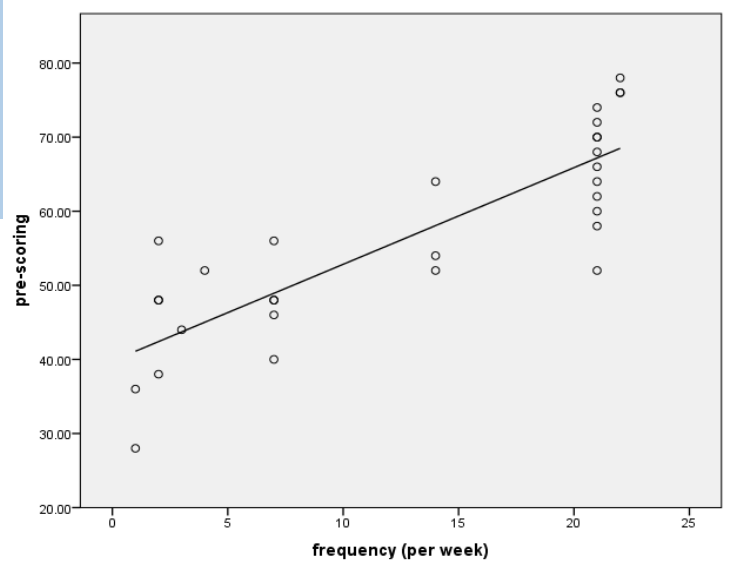

Figure (1): Correlation between frequency and pre scoring.

Only 3 patients $(10 \%)$ didn't improve from the first session but improved from the second session.

Epley's maneuver can alleviate the suffering of the patient even if it is not able to treat the patient completely.

Through this comparison, it became clear the significant of Epley's maneuver in improving the patient's lifestyle.

Table (3): Description of the grading of patients and their results after Epley in this study.

\begin{tabular}{|c|c|c|c|}
\hline & Moderate & $\begin{array}{c}\text { No. of affected } \\
\text { ears }\end{array}$ & $\%$ \\
\hline Pre-grading & $\begin{array}{c}\text { Moderately } \\
\text { severe }\end{array}$ & 10 & $30.3 \%$ \\
\cline { 2 - 4 } & severe & 4 & $57.6 \%$ \\
\hline Mild & 29 & $87.9 \%$ \\
\hline Post- & Moderate & 3 & $9.1 \%$ \\
\hline grading & Moderately & 1 & $3.0 \%$ \\
\hline $\begin{array}{c}\text { Improved } \\
\text { from 1st } \\
\text { Epley }\end{array}$ & Yes & 27 & $90.0 \%$ \\
\hline $\begin{array}{c}\text { Another } \\
\text { session }\end{array}$ & Yes & 3 & $10.0 \%$ \\
\hline $\begin{array}{c}\text { Final } \\
\text { grading in } \\
\text { 2nd Epley }\end{array}$ & Mild & 3 & $10.0 \%$ \\
\hline
\end{tabular}

The higher the patient's grade before Epley, the more he or she needs 
another treatment. This is depicted in the related table.

Accordingly, we can say that the Epley's maneuver is a very effective method in the treatment of the patients complaining of PC-BPPV.

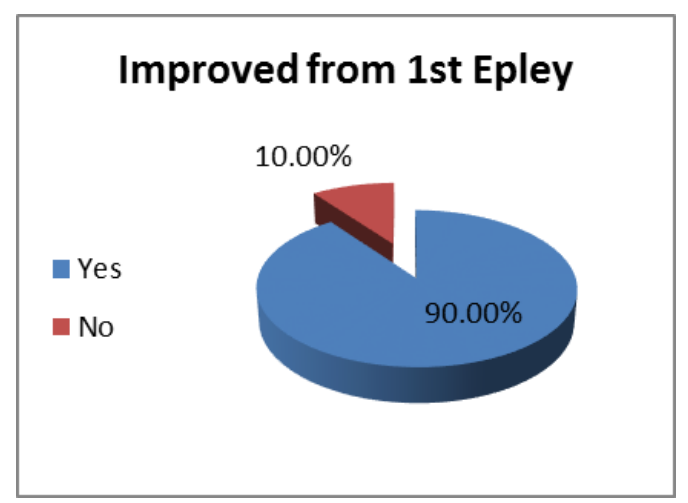

Figure (2): Pie chart showing the percentage of patients improved after first session of Epley and who needed another session in this study.

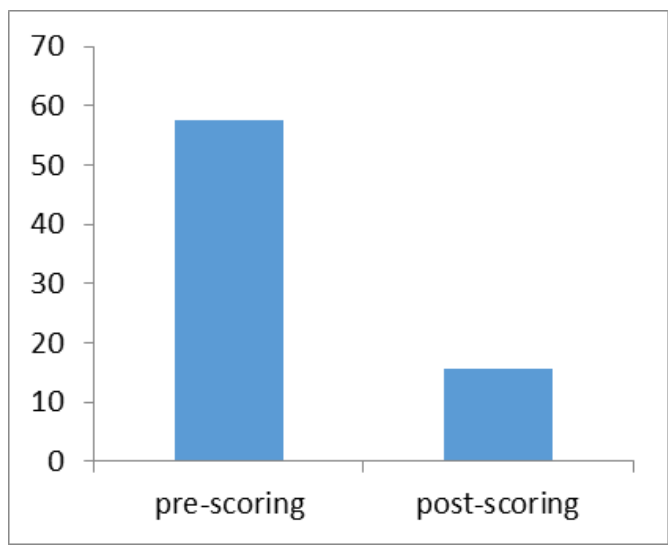

Figure (3): Bar chart of the Comparison between pre and post score in this study.

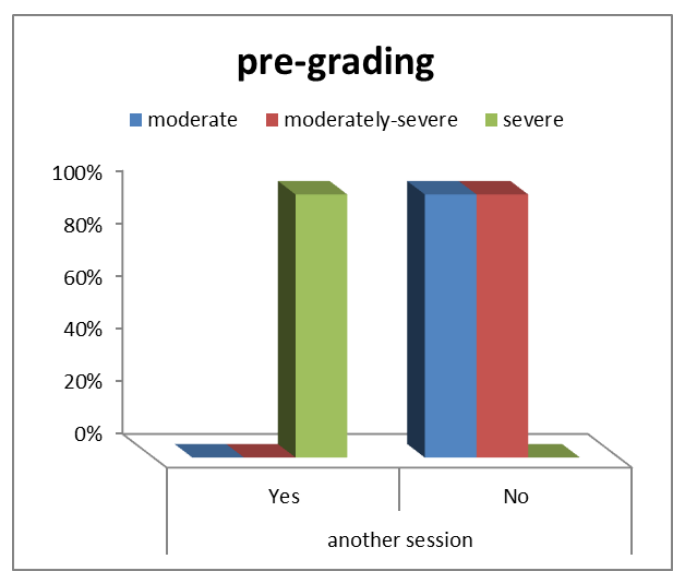

Figure (4): Bar chart of the Relation between the severity of the intial symptoms "pre-grading" and the need for repeat Epley's maneuver.
Table (4): Comparison between pre and post grading in this study.

\begin{tabular}{|c|c|c|c|c|c|c|}
\hline & & \multicolumn{2}{|c|}{ Pre } & \multicolumn{2}{|c|}{ Post } & \multirow[b]{2}{*}{$\begin{array}{c}\text { P- } \\
\text { value }\end{array}$} \\
\hline & & $\begin{array}{c}\text { No. } \\
\text { of } \\
\text { ears }\end{array}$ & $\%$ & $\begin{array}{l}\text { No. of } \\
\text { ears }\end{array}$ & $\%$ & \\
\hline \multirow{4}{*}{ Grading } & Mild & 0 & $0 \%$ & 29 & $87.9 \%$ & \multirow{4}{*}{$\underset{*}{<.001^{*}}$} \\
\hline & Moderate & 10 & $30.3 \%$ & 3 & $9.1 \%$ & \\
\hline & $\begin{array}{c}\text { Moderately } \\
\text { severe }\end{array}$ & 19 & $57.6 \%$ & 1 & $3.0 \%$ & \\
\hline & Severe & 4 & $12.1 \%$ & 0 & $0 \%$ & \\
\hline
\end{tabular}

Table (5): Outcome of this study.

\begin{tabular}{|l|l|c|c|}
\hline & & No. & $\%$ \\
\hline \multirow{2}{*}{ Outcome } & Success & 27 & $90.0 \%$ \\
\cline { 2 - 4 } & Failure & 3 & $10.0 \%$ \\
\hline
\end{tabular}

\section{Discussion :}

BPPV is the most common vestibular disorder in adults, with a lifetime prevalence of $2.4 \%^{8}$.

Approximately $90 \%$ of individuals over 65 years of age have visited their physician at least once for vertigo as their primary complaint ${ }^{9}$. The present study reviewed 30 patients with PCBPPV, 23 patients $(76.7 \%)$ were females and 7 patients $(23.3 \%)$ were males the mean age of all patients was $43.43 \pm 8.99$ (ranging from 20-60).

BPPV can be caused by either canalithiasis or cupulolithiasis and can theoretically affect each of the three semicircular canals, although superior (anterior) canal involvement is exceedingly rare. The vast majority of all BPPV cases were the posterior canal variant. The pathophysiology that causes most posterior canal BPPV cases is thought to be canalithiasis. This is probably because most freefloating endolymph debris tends to gravitate to the posterior canal, being the most gravity dependent part of the vestibular labyrinth in both the upright 
and supine positions. Once the debris enters the posterior canal, the cupular barrier at the shorter, more dependent end of the canal, blocks the exit of the debris; therefore, the debris becomes trapped and can only exit at the end without the ampulla ${ }^{10}$.

Cupulolithiasis is a condition in which debris is stuck to the cupula of a SCC, rather than being loose within the canal. It is not a treatment complication, but rather is part of the spectrum of BPPV. Cupulolithiasis might theoretically occur in any canal; horizontal, anterior or vertical, each of which might have its own pattern of positional nystagmus ${ }^{11}$. All BPPV cases in our study were due to canalithiasis so they were corrected by Epley maneuver.

BPPV affects all age groups, though it appears to be more common in the elderly. This condition seems to have a predilection for older population ${ }^{11}$. In our study the mean age for all patients was $43.43 \pm 8.99$ with an age ranging from (20-60) as shown in table (1). This agrees with all epidemiological BPPV studies of Parens, et al (2003) ${ }^{10}$, Nedzelski, et al $(\mathbf{1 9 8 6})^{13}$ and Neuhauser H. (2007) ${ }^{14}$. This can be explained by degeneration of the vestibular system of the inner ear ${ }^{15}$.

The current study confirms previous findings of a marked female preponderance among BPPV. Table (2) showed that BPPV is more common in females (23 patients representing $76.7 \%$ ) than males (7 patients representing $23.3 \%$ ). This result of gender agrees with the result of studies done by Baloh, et al. (1987) ${ }^{16}$ and Kessler, et al. (2006) ${ }^{17}$, that revealed a predominance of female patients than males among BPPV ranging from 70 to $89 \%$. This is may be related to osteoporosis and osteopenia due to altered hormone levels in females than males ${ }^{18}$.
Most patients of BPPV had unilateral affection. As shown in table (2) of this study, 27 patients (representing 90\%) of all our patients had a unilateral type of BPPV and only 3 patients (representing 10\%) had bilateral type of BPPV. This result found to be agreed with a study in the city of Sao Paulo, in which $89.1 \%$ of patients had single canal unilateral disease ${ }^{19}$.

The prevalence of the affected side in our study is not compatible with other studies. As BPPV due to left ear affection was detected in 16 patients $(59.3 \%)$ as shown in table (2), while the right ear affection was detected in 11 patients $(10.7 \%)$. These results disagreed with a study performed by Brevern, et al., (2007) ${ }^{8}$ in which there was predilection to the right-side affection. This may be due to the difference in the location of study and the nature of the country, as well as the short period of time for patient selection and follow-up.

In the present study, we found that 27 patients $(90 \%)$ required only 1 Epley's maneuver to clear their posterior canal BPPV while only 3 patients $(10 \%)$ required 2 maneuvers. These results agreed with some studies performed by Herdman, et al., $(\mathbf{1 9 9 3})^{20}$ and also Waleem, et al., $(\mathbf{2 0 0 8})^{21}$.

Although most cases of BPPV are self-limited, a number of randomized studies have shown that repositioning maneuvers are highly effective ${ }^{10}$.

A study of 36 patients diagnosed as having PC-BPPV were randomly allocated to either a PRM "particle repositioning maneuver" group or placebo treatment group with assessment at 1 month by an otologist who was unaware of the patients' treatment allocation. Resolution of vertigo was significantly higher in the PRM group (89\%) compared with the placebo group $(27 \%)^{22}$. 
Consistent with this study, another 37 consecutive cases of BPPV were treated with Epley's PRM. Ninetyseven $\%$ of patients improved, and the maneuver was well tolerated. The authors concluded that Epley's maneuver was safe and effective in the treatment of BPPV ${ }^{23}$.

However, the majority of authors are divided between performing only one maneuver per clinic visit (as in this study) and performing maneuvers until there is resolution of nystagmus or excessive patient discomfort. Objection to repeating the maneuver until there is a negative Dix-Hallpike response is because of not knowing whether the response is abolished because of a fatigue response that occurs naturally with repeated testing ${ }^{10}$.

Use of the DHI in the study sample revealed that dizziness negatively affected the quality of life of patients in all dimensions. This result agreed with Pereira, et al., (2010) ${ }^{24}$ who found that BPPV impair all the quality of life aspects and the physical scores were the most compromised aspect followed by the functional and the emotional aspects.

Comparing the pre-treatment DHI scoring of the patients and their posttreatment scoring (figure 3), we can reveal that the Epley's repositioning maneuver improves the health-related quality of life in BPPV. This result agrees with Lopaz-Escamez et al., $(\mathbf{2 0 0 3})^{25}$ who found that, PC-BPPV has a significant impact on health-related quality of life and patients experienced a decrease in quality of life as compared with normal persons.

Finally, we can say that, although BPPV is a recurring disease with a recurrence rate of approximately 15\% per year $^{26}$, we didn't face any recurrence during post treatment follow up time which is against the values of $50 \%$ and $55 \%^{28}$ reported in other studies. One limitation of our study that the follow up time since the manifestation of BPPV was less than 1 year.

\section{Conclusion} and

\section{recommendations:}

It could be concluded that PC-BPPV is common among elderly with a sex predilection for women and affecting the left side in majority of patients. And also, patient's history and physical examination "Dix-Halpike" are considered the gold standard for the diagnosis of BPPV.

In our experience, Epley's maneuver was successful in $90 \%$ of cases who presented with posterior canal BPPV. This tallies with the world literature in terms of the success rate.

Clinician should reassess patients within a week and after a month from the initial period of observation or treatment. It also requires a long follow-up period of up to a year in order to fully confirm the success of the treatment.

\section{Financial support and sponsorship:}

No financial support was obtained from any source.

\section{Conflicts of interest:}

The authors declared no potential conflicts of interest with respect to the research, authorship and/or publication of this article.

\section{Reference:}

1. Bhattacharyya N., Baugh R, Orvidas L., et al. Clinical practice guideline: benign paroxysmal positional vertigo. Otolaryngology--head and neck surgery. 2008; 139(5 Suppl 4): S47-81.

2. Sen A., Al-Deleamy L. and Kendirli T. Benign paroxysmal positional vertigo in an airline pilot. Aviat Space Environ Med. 2007; 78(11):1060-3.

3. Helminiski J. and Hain T. Evaluation and treatment of benign paroxysmal 
positional vertigo. Ann. of Long-Term Care. 2007; 15:33-39.

4. Lopez-Escamez J., Molina M., Gamiz M., et al. Multiple positional nystagmus suggests multiple canal involvement in benign paroxysmal vertigo. Acta oto-laryngologica. 2005; 125(9):954-961.

5. Fife T., Iverson D., Lempert T., et al. Practice parameter: therapies for benign paroxysmal positional vertigo (an evidence-based review): Neurology. 2008; 70(22):2067-2074.

6. Whitney S., Marchetti G. and Morris L. Usefulness of the dizziness handicap inventory in the screening for benign paroxysmal positional vertigo. Otology \& neurotology. 2005; 26(5):1027-1033.

7. ElGohary M., Tawfik S. and Ghouneim M. Clinical measures of equilibrium versus computerized dynamic posturogrophy in balance disorder patients. 2000; Unpublished MS Thesis, Faculty of Medicine, Ain Shams University.

8. Brevern M., Radtje A., Lezius F., Feldmann M., Zeise T., Lempert T. and Neuhauser H. Epidemiology of benign paroxysmal positional vertigo: apopulation based study. Neurol Neurosurg Psychiatry J. 2007; 78:710715.

9. Goebel A. Mangement options for acute versus chronic vertigo. Otolaryngolgic Clinic of North America. 2000; 33 (3.)

10.Parnes L., Agrawal S. and Atlas J. Diagnosis and management of benign paroxysmal positional vertigo (BPPV). Canad. Med. Assoc. J. 2003; 169 (7):681-693.

11.Hain T. Head-shaking Nystagmus and New Technology (Editorial). Neurology. 2007; 68: 17, 1333-1334.

12.Marciano E. and Marcelli V. Postural restrictions in labyrintholithiasis. European Archives of OtoRhinoLaryngology. 2002; 259(5): 262-265.

13.Nedzelski J., Barber H. and Mcilmoyl L. Diagnosis of benign paroxysmal positioning vertigo in dizziness unit. J.Otolaryngol. 1986; 15: 101-4.

14. Neuhauser H. Epidemiology of vertigo. Curr Opin Neurol. 2007; 20:40-6.
15.Hain T., Squires T. and Stone H. Clinical implications of a mathematical model of benign paroxysmal positional vertigo. Ann N Y Acad Sci1. 2005; 039: 384-94.

16.Baloh R., Honrubia V. and Jacobson K. Benign positional vertigo: clinical and oculographic features in 240 cases. Neurol. 1987; 37:371- 378.

17.Kessler N., Lurago V., Rasque J., Borges L., Gananca C. and Campos C. Benign paroxysmal positional vertigo in patients undergoing otological surgery. Acta ORL. 2006; 24(1): 6-9.

18. Vibert D., KompiscM. And Hausler R. Benign paroxysmal positioning vertigo in older women may be related to osteoporosis and osteopenia. Ann Otol Rhinol Laryngol. Oct. 2003; 112(10): 855-9.

19.Silveira M., Gananca C., Gananca M. and Caovilla H. Bilateral monocanal Benign paroxysmal positional vertigo. Acta ORL. 2007; 25(2): 124-7.

20.Herdman S., Tusa R., Zee D., Proctor L. and Mattex D. Single treatment approaches to benign paroxysmal positional vertigo. Arch. Otolaryngol. Head Neck Surg. 1993; 119:450-454.

21. Waleem S., Malik S., Ulah S. and Hassan Z. Office management of benign paroxysmal positional vertigo with Epley's maneuver. Journal of Ayub Medical College, Abbottabad. 2008; 20(1): 77-79.

22.Lynn S., Pool A., Rose D., Brey R. and Suman V. Randomized trial of the canalith repositioning procedure. Otolaryngol. Head Neck Surg. 1995; 112:670-5.

23.Perez Vazquez P., Manrique Estrada C., Munoz Pinto C., Baragano, Rio L., Bernardo Corte M. and Suarez Nieto C. Treating benign paroxysmal positional vertigo with the canalith repositioning maneuver of Epley, our experience. Acta Otorhinolaryngol. Esp. 2001; 52(3):193-8.

24.Pereira A., Santos J. and Volpe F. Effect of Epley's maneuver on the quality of life of paroxysmal positional benign vertigo patients. Braz J. Otorhinolaryngol. 2010; 76(6): 704-8.

25.Lopez-Escamez, Jose A., Gamiz., Maria J. and Fernandez-Perez. Impact 
of treatment on health-related quality of life in patients with posterior canal benign paroxysmal positioning vertigo. Otologyy \& Neurotology J. 2003; 24(4): pp 637-61.

26.Nunez R., Cass S. and Furman J. Shortand long-term outcomes of canalith repositioning for benign paroxysmal positional vertigo. Otolaryngol Head and Neck Surg 2000; 122: 647-652.

27.Brandt T., Huppert D., Hecht J., et al. Benign paroxysmal positional vertigo, a long-term follow up (6-17 ears) of 125 patients. Acta Otolaryngol. 2006; 126: $160-163$.

28. Korres S. and Balatsouras D. Diagnostic, pathophysiologic and therapeutic aspects of benign paroxysmal positional vertigo. Otolaryngol Head and Neck Surg. 2004; 131: 438-44. 

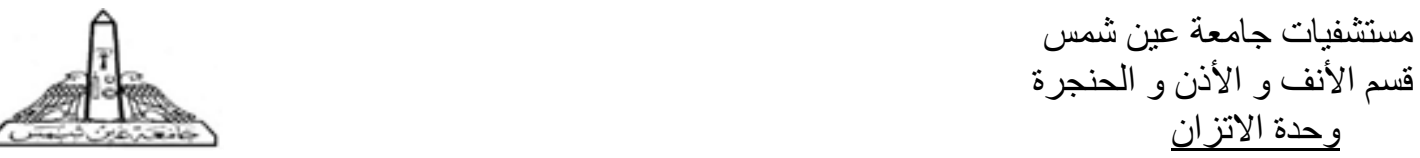

تحديد درجة الإعاقة لمرضى الدوار

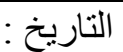

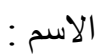

Tel :

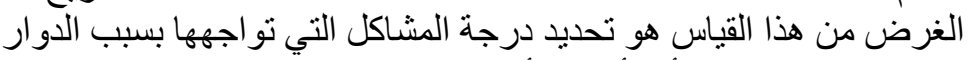

Diagnosis:

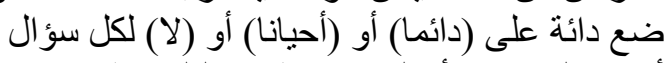

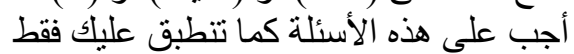

\begin{tabular}{|c|c|c|c|c|c|}
\hline & & & & & \\
\hline $\mathrm{P}$ & $\bar{\gamma}$ & أحيانا & دائما & هل النظر الى أعلى يزيد الدو ار & 1 \\
\hline $\mathrm{E}$ & ע & 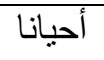 & دائما & هل تشعر بالاحباط بسبب هذه المشكلة & 2 \\
\hline $\mathrm{F}$ & ע & أحيانا & دائما & هل قللت من أعمالك و أسفارك بسبب الدوار & 3 \\
\hline $\mathrm{P}$ & 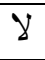 & أحيانا & دائما & هل السير في ممشى ضيق كالسوبر ماركت مثلا يزيد الدوار & 4 \\
\hline $\mathrm{F}$ & 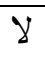 & أحيانا & دائما & هل تجد صعوبة في القيام من السؤيؤ أو الذهاب اليه & 5 \\
\hline $\mathrm{F}$ & ע & أحيانا & دائما & هل قللت من أنشطتاك الاجتماعية مثل الخروج للنز هة أو للزيار ات & 6 \\
\hline $\mathrm{F}$ & ע & 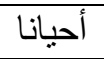 & دائما & هل تجد صعوبة أثناء ركوب المو اصلات & 7 \\
\hline $\mathrm{P}$ & 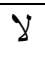 & أحيانا & دائما & هل زيادة المجهود أو الرياضة تزيد من الدوار & 8 \\
\hline $\mathrm{E}$ & 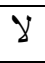 & 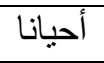 & دائما & هل تخشى الخروج بمفردك بسبب الدوار & 9 \\
\hline $\mathrm{E}$ & 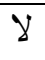 & أحيانا & دائما & هل تشعر بالحرج أمام الأخرين بسبب الدوار & 10 \\
\hline $\mathrm{P}$ & ע & 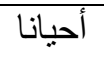 & دائما & هل تشعر بالدو ار عندما تحرك ر أسك بسر عة & 11 \\
\hline $\mathrm{F}$ & $y$ & 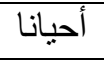 & دائما & هل تبتعد عن الأماكن المرتفعة بسبب الدوار & 12 \\
\hline $\mathrm{P}$ & $y$ & أحيانا & دائما & هل تشعر بالدوار عندما تتقلب في السرير & 13 \\
\hline $\mathrm{F}$ & $y$ & 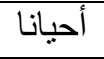 & دائما & هل بسبب الدوار لا تسنطيع زيادة العمل المكلف به & 14 \\
\hline $\mathrm{E}$ & 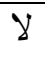 & أحيانا & دائما & هل تخشى أن يظن الناس بك انك تتعاطى مهدئات أو ما شابه & 15 \\
\hline $\mathrm{F}$ & $y$ & 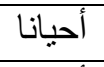 & دائما & هل بسبب الدو ار تخشى المشي بمفردك & 16 \\
\hline $\mathrm{P}$ & 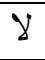 & أحيانا & دائما & هل النزول من السلم يزيد الدو ار & 17 \\
\hline $\mathrm{E}$ & $\gamma$ & 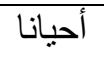 & دائما & هل تجد صعوبة في التركيز بسبب الدوار & 18 \\
\hline $\mathrm{F}$ & $y$ & 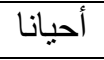 & دائما & هل تجد صعوبة في المشي في الظلام & 19 \\
\hline $\mathrm{E}$ & 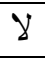 & أحيانا & دائما & هل تشعر بالخوف من البقاء بمفردك بالمنزل & 20 \\
\hline $\mathrm{E}$ & 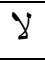 & أحيانا & دائما & هل تشعر أنكا أصبحت معاقا بسبب الدوار & 21 \\
\hline $\mathrm{E}$ & $y$ & 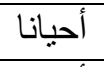 & دائما & هل أصبحت بسبب الدوار سريع الانفعال مع أقاربك أو أصدقائك & 22 \\
\hline $\mathrm{E}$ & $\bar{\gamma}$ & أحيانا & دائما & هل أصـابك الدوار بالاكتئاب & 23 \\
\hline $\mathrm{F}$ & $y$ & أحيانا & دائما & هل أثر عليك في القيام بمسؤليتلك & 24 \\
\hline $\mathrm{P}$ & $y$ & أحيانا & دائما & هل الانحناء يزيد من الدوار & 25 \\
\hline
\end{tabular}

F score ......... E score ......... P score ......... Total ..........

Arabic translated Dizziness Handicap Inventory of El Gohary***...

** ElGohary M., Tawfik S. and Ghouneim M. Clinical measures of equilibrium versus computerized dynamic posturogrophy in balance disorder patients. 2000; Unpublished MS Thesis, Faculty of Medicine, Ain Shams University. 